\title{
Ultrasound-guided fine needle aspiration cytology of Para-aortic lymph node metastasis in uterine cervical cancer: diagnostic accuracy and impact on clinical decision making
}

\author{
Junping Liu', Xin Liu', Zhengying Guo², Xiaojuan LV³, Weimin Mao ${ }^{4}$, Dong Xu and Lijing Wang ${ }^{1 *}$
}

\begin{abstract}
Objective: The main aim of this study was to ascertain the effectiveness of ultrasound-guided fine needle aspiration cytology (US-FNAC) in the diagnosis of para-aortic lymph node (PALN) metastasis in uterine cervical cancer and to establish its potential impact on clinical therapeutic decision making.

Methods: We retrospectively reviewed clinical data from 92 patients diagnosed with cervical cancer with PALN enlargement between 2010 and 2018. Cytological results obtained with US-FNAC were classified by the same experienced cellular pathologists. Diagnostic indicators were determined on the basis of biopsy, imaging and clinical follow-up results. Univariate and multivariate analyses were used to assess the differences of influencing factors. The effect of US-FNAC on clinical decision making was evaluated.

Results: Cytological results of US-FNAC were categorized as malignancy $(n=62 ; 67.4 \%)$, suspicious malignancy $(n=$ $11 ; 12.0 \%)$, undetermined $(n=5 ; 5.4 \%)$, benign $(n=10 ; 10.9 \%)$, and inadequate $(n=4 ; 4.3 \%)$. Satisfactory biopsy samples were obtained from $95.7 \%$ of PALNs sampled (88/92). The sensitivity, specificity, positive predictive value, negative predictive value and accuracy of FNAC in distinguishing benign from malignant cases were 90.1\% (95\% Cl: $0.809-0.953), 100 \%$ (95\% Cl: $0.561-1), 100 \%$ (95\% Cl: $0.938-1)$, 46.7\% (95\% Cl: $0.223-0.726)$ and $90.9 \%$ (95\% Cl: $0.848-$ 0.970), respectively. Univariate analysis indicated significant differences in experience of puncture physicians (radiologists) between the correct and wrong diagnosis groups $(P<0.05)$, which was further confirmed as an independent predictor of diagnostic accuracy in multivariate analysis ( $p=0.031, \mathrm{OR}=0.077,95 \% \mathrm{Cl}$ : 0.354-0.919). All patients tolerated the US-FNAC procedure well and only nine presented slight abdominal discomfort. The therapeutic strategies for 74 patients (80.4\%) were influenced by US-FNAC findings.
\end{abstract}

\footnotetext{
* Correspondence: wanglj844@zjcc.org.cn

'Department of Ultrasound, Cancer Hospital of the University of Chinese Academy of Sciences (Zhejiang Cancer Hospital), No.1 East Banshan Road, Gongshu District, Hangzhou 310022, Zhejiang Province, China

Full list of author information is available at the end of the article
}

(c) The Author(s). 2021 Open Access This article is licensed under a Creative Commons Attribution 4.0 International License, which permits use, sharing, adaptation, distribution and reproduction in any medium or format, as long as you give appropriate credit to the original author(s) and the source, provide a link to the Creative Commons licence, and indicate if changes were made. The images or other third party material in this article are included in the article's Creative Commons. licence, unless indicated otherwise in a credit line to the material. If material is not included in the article's Creative Commons licence and your intended use is not permitted by statutory regulation or exceeds the permitted use, you will need to obtain permission directly from the copyright holder. To view a copy of this licence, visit http://creativecommons.org/licenses/by/4.0/ The Creative Commons Public Domain Dedication waiver (http://creativecommons.org/publicdomain/zero/1.0/) applies to the data made available in this article, unless otherwise stated in a credit line to the data. 
Conclusions: US-FNAC was a relatively safe and effective technique for examination of enlarged para-aortic lymph nodes and may therefore serve as a routine diagnostic tool to guide clinical decision making for management of cervical cancer.

Keywords: Cervical cancer, Para-aortic lymph node metastases, Fine needle aspiration cytology, Diagnosis accuracy, Ultrasound

\section{Materials and methods}

\section{Patients}

This study was approved by the Ethics Committee of Zhejiang Cancer Hospital and conducted in accordance with the ethical standards of the 1964 Helsinki Declaration. The need for informed consent from all patients was waived due to the retrospective nature of the study. We used the key words "retroperitoneal," "para-aortic lymph node," "biopsy," and "aspiration" to screen an interventional ultrasound database between January 1, 2010, and December 30, 2018. Figure 1 depicts the workflow used for inclusion and exclusion of cases. According to the criteria used, 240 cases were excluded and we consecutively enrolled 92 patients with PALNs from cervical cancer referred to our department for USFNAC by gynecological oncologists who required pathological results for guidance of patient treatment.

\section{Ultrasound examination}

Initially, each patient underwent a detailed ultrasound examination to determine the feasibility of FNAC. The size, number, location and characteristics of the affected lymph nodes were assessed using GE-E9 $(5-16 \mathrm{MHz})$ and Esaote MyLab Twice (4-12 MHz). The locations of PALNs for puncturing were divided into four regions (designated levels I-IV) based on anatomical structure [2] (Fig. 2). The nodule size was measured in the central section of the cross-sectional image, taking the diameter perpendicular to the abdominal aorta as the length. Lymph nodes with safe puncture paths and highly suspicious morphology were considered suitable puncture targets. During US-FNAC, necrotic areas were avoided as much as possible. In order to avoid damaging vessels, color Doppler was used to confirm the safest puncture path.

\section{US-FNAC procedure}

Prior to puncture, all patients were subjected to coagulation status screening (international standardized ratio was $<1.6$, prothrombin time $<15 \mathrm{~s}$, partial thromboplastin time $<45 \mathrm{~s}$, platelet count $>80,000$ per $\mathrm{mm}^{3}$ ). Informed consent for the US-FNAC procedure was obtained from all patients. Punctures were carried out by five radiologists familiar with the FNAC process. The site of puncture was marked on the skin and the area cleaned with povidone-iodine solution. Following local anesthesia with $2 \%$ lidocaine, US-FNAC was performed using a 20-23 gauge needle (Hakko Co, Japan) and attached to an empty $5 \mathrm{~mL}$ plastic syringe using negative suction with at least one pass (Fig. 3). All operators used a free-hand technique (without biopsy attachment). Onsite cytology evaluation was not performed in our department. Patients were required to be in the hospital and monitored for vital signs and complications.

Cellular material was subsequently expelled onto a glass slide that was immediately immersed in 95\% alcohol. In some cases, cell blocking was conducted. Specimens were sent to the cytology department and stained using the hematoxylin and eosin method to determine color changes in the refractive index of the fine structure of the cell. Final cytology diagnosis was made by the same cellular pathologists with more than 10 years of experience.

\section{FNAC categorization and final diagnosis}

FNAC results were classified into the following groups: unsatisfactory/non-diagnostic material for diagnosis (i, inadequate group), benign or reactive change (ii, benign group), atypical cells present but indeterminate for benign and malignancy (iii, undetermined group), suspicious for malignancy (iv, suspicious group), and positive for malignancy ( $v$, malignant group). An unsatisfactory/ non-diagnostic result (i) was defined in cases where the sample consisted only of the blood component or an acellular specimen. Results were considered benign (ii) when mature lymphocytes in terms of morphology or linear colloid-like substance (foreign body granuloma) were obtained from aspirated nodules. Undetermined results (iii) were obtained for samples that consisted exclusively of a small amount of atypical cell components but no conclusive benign and malignancy status. In cases where cytological findings were indicative of suspected or unequivocal malignancy, diagnosis was "suspicious for malignancy" (iv) and "positive for malignancy" (v), respectively. Unsatisfactory/non-diagnostic results (i) were defined as "inadequate" "and the remaining results as "adequate/satisfactory" specimens. Final diagnoses were confirmed in cases of $\mathrm{i}$, ii and iii via repeat biopsy, surgery, imaging, clinical indicators, and clinical follow-up analyses [15]. 
Prepare for Ultrasound-guided interventional procedure in

retroperitoneal masses $(n=332)$
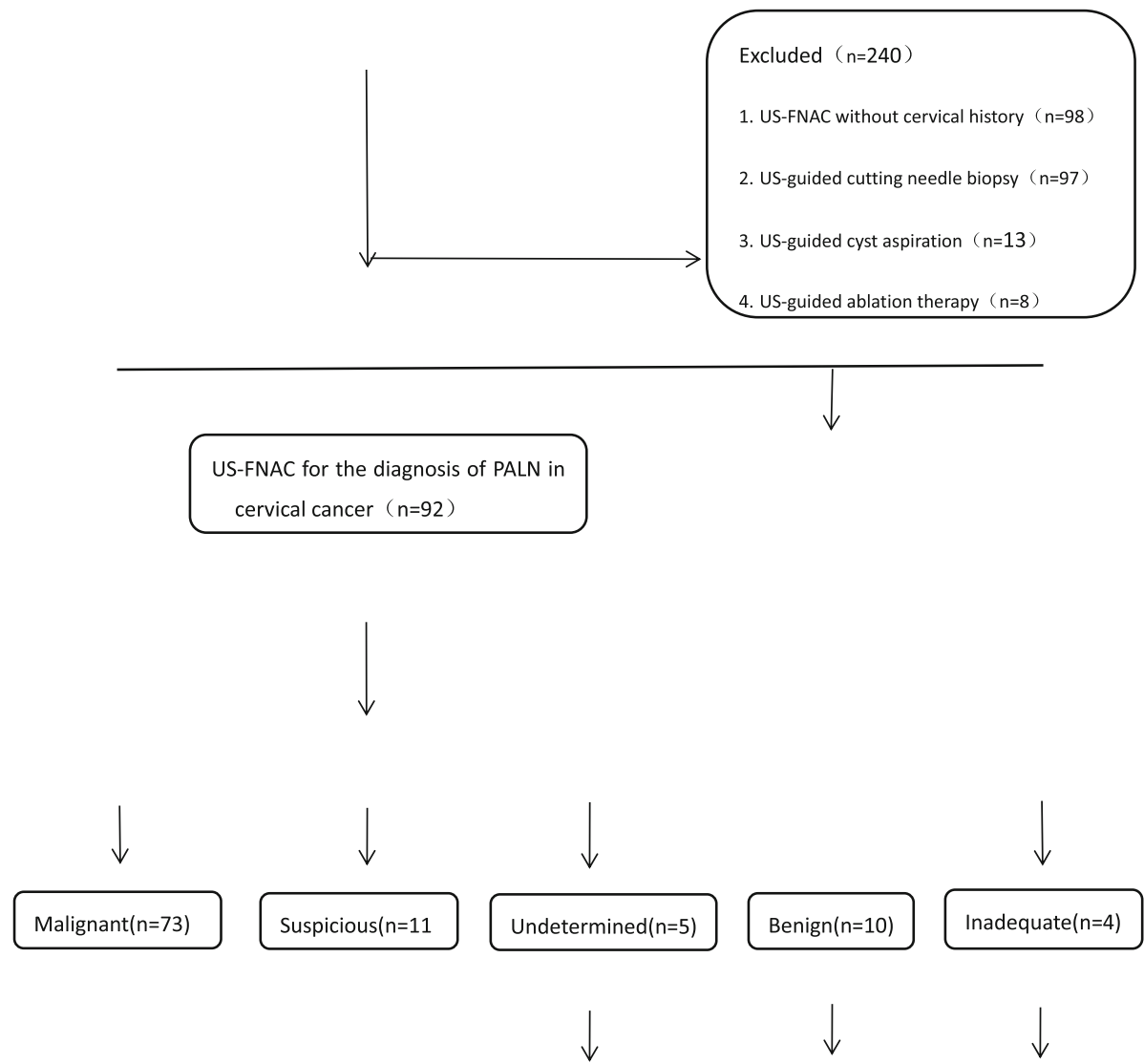

$\operatorname{Benign}(n=10)$

nadequate $(n=4)$

Repeat biopsy, surgery, imaging , and clinical follow-up analyses

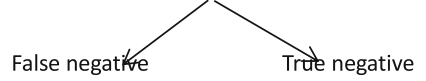

Malignancy $(n=11)$

Benign $(n=8)$

Fig. 1 Flow chart of US-FNAC from 2010 to 2018 for diagnosis of PALN in cervical cancer

\section{Statistical analysis}

Cases of malignancy (iv, v) were considered true-positive diagnoses. In cases where shrinkage, disappearance, or stationary condition was presented for a period of $12-$ 24 months without specific treatment during follow-up imaging or if subsequent re-biopsy or surgery indicated a benign pathologic result (i, ii, iii), a true-negative result was recorded. A false-negative result (i, ii, iii) was defined in cases where nodes were obviously enlarged in follow-up imaging, malignant results were confirmed with surgery and re-biopsy or clinical data were highly suggestive of malignancy. False-negative results were considered incorrect diagnoses. The evaluation index of diagnostic testing incorporated specificity, sensitivity, negative predictive value (NPV), positive predictive value (PPV) and accuracy parameters, which were calculated based on previous definitions.

Continuous variables were expressed as means \pm standard deviation and statistical analysis performed using ANOVA. Categorical variables were presented on the basis of frequency and percentage and the analysis performed using chi-square or Fisher's exact test. Univariate analysis (chi-square or a Fisher exact test) was conducted to investigate the relationships among experience, age, body mass index, nodal size, nodal number, lesion location, needle size, cell block, nature and period 


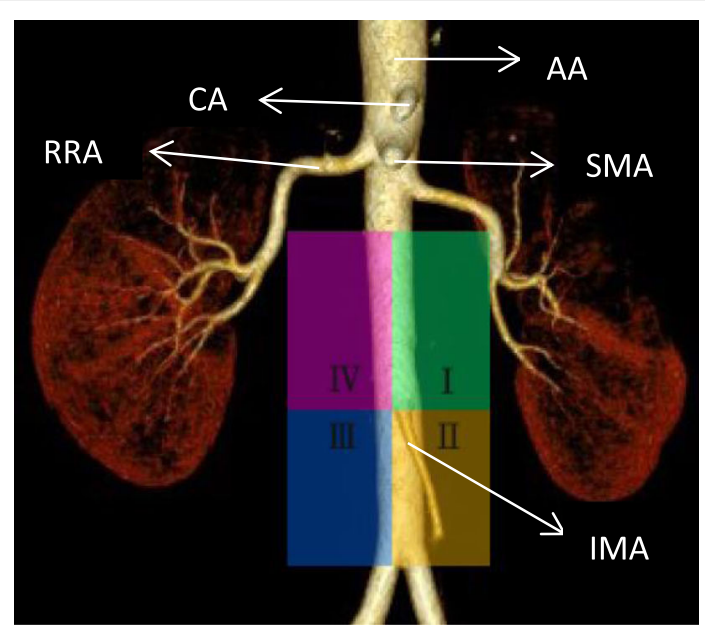

\section{$\mathrm{SMA}=$ Superior mesenteric artery $\quad \mathrm{AA}=\mathrm{Abdominal}$ aorta $\quad \mathrm{RRA}=$ Right renal artery}

\section{IMA=Inferior mesenteric artery $\quad C A=C e l i a c$ axis}

Fig. 2 Schematic diagram of the anatomical distribution of the para-aortic lymph nodes. SMA = Superior mesenteric artery $A A=A b d o m i n a l$ aorta RRA = Right renal artery. IMA = Inferior mesenteric artery $C A=$ Celiac axis

of treatment. Multivariate logistic regression analysis was additionally used to determine variables independently contributing to the diagnostic yield of sampling. Differences were considered statistically significant at $P<0.05$. SPSS software (version 21.0 for Windows; SPSS, Chicago, IL, USA) was used for all statistical analyses.

\section{Results}

\section{General clinical data}

Overall, 24 patients with cervical cancer were excluded (Fig. 1). In 16 of the 24 cases, enlarged lymph nodes observed via CT imaging could not be visualized with conventional ultrasound. In five of the cases, US-FNAC could not be performed due to small node sizes $(<10$ $\mathrm{mm})$. There were no safe access paths for puncture to avoid injury to major vessels in three patients. Among the 92 included cases, patient ages ranged from 25 to 80 years (mean: $51.5 \pm 10.8$ years). The node sizes ranged from $11 \mathrm{~mm}$ to $28 \mathrm{~mm}$ (average: $17.1 \pm 4.0 \mathrm{~mm}$ ). Body mass index (BMI) ranged from 14.6 to 32.0 (mean: $22.0 \pm 3.4)$. In 79 cases $(85.9 \%)$, multiple nodes were present while a solitary node was detected in 13 cases (14.1\%). The $20 \mathrm{G}$ and $21 \mathrm{G}$ fine needles were used for the US-FNAC procedure in 60 cases. Biopsies was performed with $22 \mathrm{G}$ and $23 \mathrm{G}$ needles using a suction syringe in 32 cases.

In terms of anatomical grouping, PALNs were divided into left and right distributions based on the abdominal aorta. The inferior mesenteric artery was taken as the boundary level dividing the upper and lower regions
(Fig. 2). Overall, 55 cases were in the left para-aortic region (level I: 27 cases and level II: 28 cases) and 37 cases in the right para-aortic region (level III: 29 cases and level IV: 8 cases; Table 1).

\section{Cytological findings and final diagnosis}

Biopsy-based cytological findings were as follows: malignant $(n=62 ; 67.4 \%)$, suspicious $(n=11 ; 12.0 \%)$, undetermined $(n=5 ; 5.4 \%)$, benign $(n=10 ; 10.9 \%)$, and unsatisfactory $(n=4 ; 4.3 \%)$. In two undetermined and one inadequate cases, repeat US-FNAC was performed, which provided sufficient evidence for confirmed diagnosis of squamous cell carcinoma. The remaining three undetermined and two inadequate cases were confirmed as malignant based on clinical follow-up and imaging analyses. However, a final benign diagnosis was established in one inadequate case due to obvious tumor shrinkage at 4 months follow-up. Therefore, among nine samples, eight were finally diagnosed as malignant (falsenegative) and 1 as benign (true-negative) (Table 2).

Ten cases were diagnosed as benign based on USFNAC (Fig. 4a). Three of the benign cases were further subjected to surgical resection for therapeutic and diagnostic purposes, leading to definitive malignant diagnosis. The final diagnosis of the remaining seven benign FNAC cases was confirmed as benign based on clinical follow-up and imaging. No false-positive results were obtained. Therefore, final diagnosis of the 10 benign samples re-examined was malignant for three (falsenegative) and benign for seven (true-negative) cases. 


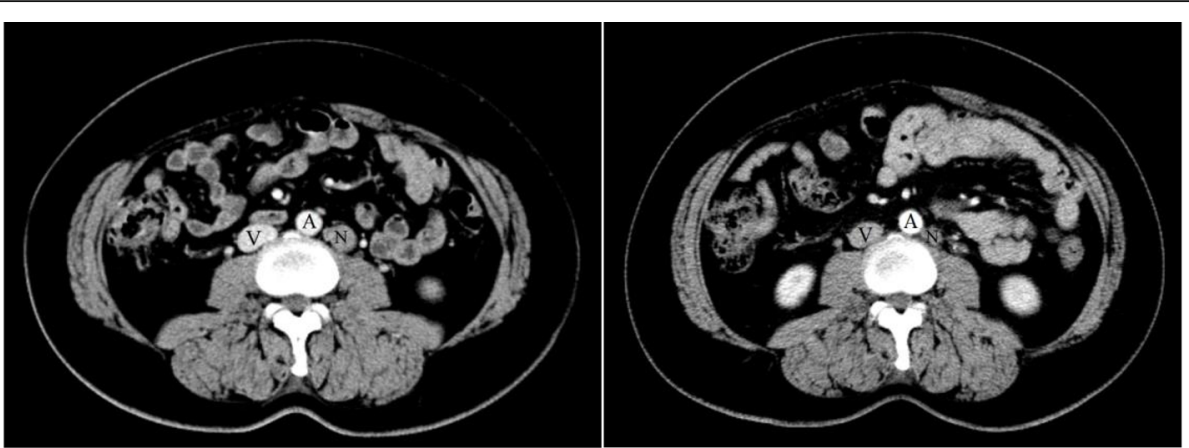

a.

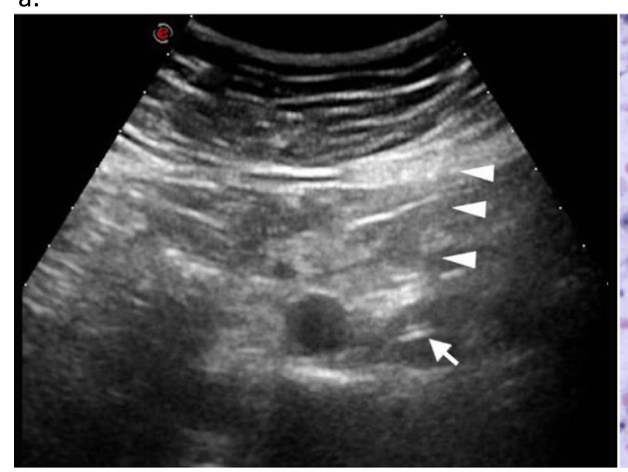

c. b.

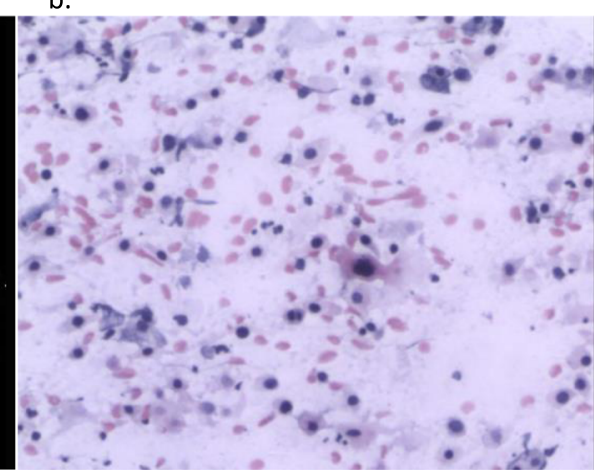

d.

$\mathrm{A}=$ aorta; $\mathrm{V}=$ Inferior vena cava; $\mathrm{N}=$ Lymph node

Fig. 3 US-FNAC and therapeutical effect of a para-aortic lymph node. a a 49-year-old woman with metastatic squamous carcinoma from cervical cancer presents with a $16 \mathrm{~mm}$ Lymph node located left paraaortic region above the inferior mesenteric artery (I). b After 5 months of radiotherapy, the size of lymph nodes are significantly reduced. c Needle tip (arrow) is clearly defined as being within the Lymph node and conventional US displays the pass of the puncture needle through the mesentery or bowels (arrowhead). $\mathbf{d}$ The FNAC results was diagnosed as metastatic squamous cell carcinoma with scattered atypical cells, necrosis and cytokeratinization (HE stain, $\times 20)$. = aorta; $V=$ Inferior vena cava; $\mathrm{N}=$ Lymph node

Eighty-eight (95.7\%) biopsy specimens were regarded as satisfactory samples by more than 10 experienced cytopathologists. Among the 73 malignant specimens diagnosed using FNAC, 62 were unambiguously confirmed as malignant, including five adenocarcinoma (Fig. 4b), 39 squamous cell carcinoma (Fig. 4c), and 18 undifferentiated metastatic carcinoma (Fig. 4d), while 11 were diagnosed as probable metastatic carcinoma. According to the definition (iv, v), all 73 cases were finally diagnosed as malignant (true-positive).

\section{Accuracy of US-FNAC}

Due to variable definitions of false-negative and truenegative adopted previously for assessing diagnostic accuracy [16], we used the analytical methods described below for data presentation in this study. Upon exclusion of the four inadequate cases from our analyses and taking undetermined specimens as negative cytological results, the true-positive, false-positive, false-negative and true-negative values obtained were $73,0,8$ and 7 , respectively. The sensitivity, specificity,
PPV, NPV and accuracy of FNAC in distinguishing benign from malignant cases were determined as 90.1\% (95\% CI: $0.809-0.953), 100 \%$ (95\% CI: 0.561-1), 100\% (95\% CI: $0.938-1$ ), 46.7\% (95\% CI:0.223-0.726) and $90.9 \%$ (95\% CI:0.848-0.970), respectively. Upon exclusion of the five cases with undetermined cytologic diagnosis, true-positive, false-positive, falsenegative and true-negative values obtained were 73,0 , 3 and 7, respectively. The sensitivity, specificity, PPV, NPV and accuracy of FNAC in distinguishing benign from malignant cases were determined as $96.1 \%$ (95\% CI:0.881-0.990), 100\% (95\% CI:0.561-1), 100\% (95\% CI: $0.938-1)$, $70.0 \%$ (95\% CI: $0.354-0.919)$ and $96.4 \%$ (95\% CI: $0.923-1)$, respectively. We observed no significant differences between the two methods (Table 3).

\section{Factors influencing diagnostic accuracy}

Correct diagnosis $(n=81)$ and incorrect diagnosis (false negative cases, $n=11$ ) groups in relation to variables affecting diagnostic accuracy are presented in Table 4 . 
Experience refers to the years of engaging in interventional ultrasound. Univariate analysis revealed that the diagnostic accuracy of US-FNAC was significantly related to experience ( 5 y vs. $>5$ y; $p=0.008$ ), but not age, body mass index ( $\leq 24$ vs. $>24$ ), nodal size $(\leq 15 \mathrm{~mm}$ vs. $>15 \mathrm{~mm}$ ), nodal number (multiple vs. solitary), lesion location (left para-aortic vs. right para-aortic), needle size ( $\leq 21 \mathrm{G}$ vs. $\geq 22 \mathrm{G}$ ), cell block (yes vs. no), nature (malignant vs. benign) and period treatment(2010-2015 vs. 2016-2018) $(p>0.05)$. Multivariate logistic regression analysis further validated the correlation between more experienced operators and correct diagnosis $(p=0.031$, OR = 0.077, 95\% CI: 0.354-0.919; Table 4).

\section{Complications}

All patients tolerated the US-FNAC procedure well. No major complications were encountered during the procedure, such as bleeding, perforation and infection. Nine patients presented with slight abdominal discomfort, which was relieved after 1 hour of clinical observation. No further clinical treatment was required.
Table 2 The diagnostic categorizations of initial US-FNAC in PLANs and final diagnosis

\begin{tabular}{llll}
\hline $\begin{array}{l}\text { Diagnosis } \\
\text { category } \\
\begin{array}{l}\text { Cytology by } \\
\text { US-FNAC }\end{array}\end{array}$ & $\begin{array}{l}\text { Malignant } \\
(\boldsymbol{n}=\mathbf{8 4})\end{array}$ & $\begin{array}{l}\text { Nonmalignant } \\
(\boldsymbol{n}=\mathbf{8})\end{array}$ & $\begin{array}{l}\text { Total } \\
(\boldsymbol{n}=\mathbf{9 2})\end{array}$ \\
\hline Malignant & $62(67.4 \%)$ & $0(0.0 \%)$ & 62 \\
Suspicious & $11(11.9 \%)$ & $0(0.0 \%)$ & 11 \\
Undetermined & $5(5.4 \%)$ & $0(0.0 \%)$ & 5 \\
Benign & $3(3.3 \%)$ & $7(7.6 \%)$ & 10 \\
inadequate & $3(3.3 \%)$ & $1(1.1 \%)$ & 4
\end{tabular}

Final diagnoses were confirmed by at least two experts, including radiooncologists, imaging specialists, and pathologists [15]. US-FNAC ultrasound guided fine-needle aspiration cytology, PALNs para-aortic lymph nodes

\section{Impact of US-FNAC on clinical decision making}

Radiotherapy, chemotherapy, and surgery (laparoscopy or laparotomy) are commonly used for patients with PALN metastases from cervical cancer. After US-FNAC, among 73 patients with cytological malignancy, 59 were subjected to PALN radiotherapy and systemic chemotherapy and only nine received chemotherapy. PALN

Table 1 Comparision of demographics and lesion distribution among the five groups

\begin{tabular}{|c|c|c|c|c|c|c|c|}
\hline Characteristics Group & $\begin{array}{l}\text { Total } \\
(n=92)\end{array}$ & $\begin{array}{l}\text { Malignant } \\
(n=62)\end{array}$ & $\begin{array}{l}\text { Suspicious } \\
(n=11)\end{array}$ & $\begin{array}{l}\text { Undetermined } \\
(n=5)\end{array}$ & $\begin{array}{l}\text { Benign } \\
(n=10)\end{array}$ & $\begin{array}{l}\text { Inadequate } \\
(n=4)\end{array}$ & $P$ value \\
\hline Age $[\bar{x} \pm s]($ year $)$ & $51.5 \pm 10.8$ & $50.9 \pm 9.4$ & $58.6 \pm 15.5$ & $52.8 \pm 15.5$ & $46.0 \pm 8.8$ & $54.5 \pm 7.4$ & 0.087 \\
\hline Body mass index & $22.0 \pm 3.4$ & $21.7 \pm 3.4$ & $23.7 \pm 5.0$ & $22.9 \pm 1.6$ & $21.5 \pm 2.1$ & $20.8 \pm 1.6$ & 0.302 \\
\hline Lesion size (mm) & $17.1 \pm 4.0$ & $17.6 \pm 3.8$ & $18.0 \pm 4.7$ & $16.0 \pm 4.0$ & $14.6 \pm 3.1$ & $13.8 \pm 3.2$ & 0.061 \\
\hline Nodal number & & & & & & & 1.000 \\
\hline solitary & $13(14.1 \%)$ & $7(7.6 \%)$ & $1(1.1 \%)$ & $0(0.0 \%)$ & $4(4.3 \%)$ & $1(1.1 \%)$ & \\
\hline multiple & $79(85.9 \%)$ & $55(59.8 \%)$ & $10(10.9 \%)$ & $5(5.4 \%)$ & $6(6.5 \%)$ & $3(3.3 \%)$ & \\
\hline \multicolumn{8}{|l|}{ Location } \\
\hline \multicolumn{8}{|l|}{ Left Paraaortic } \\
\hline Above the $\mid \mathrm{MA}(\mathrm{I})$ & $27(29.3 \%)$ & $18(19.5 \%)$ & $5(5.4 \%)$ & $1(1.1 \%)$ & $0(0.0 \%)$ & $3(3.3 \%)$ & 0.670 \\
\hline Below the IMA (II) & $28(30.5 \%)$ & 19 (20.7\%) & $4(4.3 \%)$ & $1(1.1 \%)$ & $3(3.3 \%)$ & $1(1.1 \%)$ & \\
\hline \multicolumn{8}{|l|}{ Right Paraaortic } \\
\hline Below the IMA (III) & $29(31.5 \%)$ & $18(19.5 \%)$ & $2(2.2 \%)$ & $3(3.3 \%)$ & $6(6.5 \%)$ & $0(0.0 \%)$ & 1.000 \\
\hline Above the IMA (IV) & $8(8.7 \%)$ & $7(7.6 \%)$ & $0(0.0 \%)$ & $0(0.0 \%)$ & $1(1.1 \%)$ & $0(0.0 \%)$ & \\
\hline \multicolumn{8}{|l|}{ Needle gauge } \\
\hline$\leq 21 \mathrm{G}(20 \mathrm{G}, 21 \mathrm{G})$ & $60(65.2 \%)$ & $40(43.5 \%)$ & $8(8.7 \%)$ & $4(4.3 \%)$ & $6(6.5 \%)$ & $2(2.2 \%)$ & 1.000 \\
\hline$\geq 22 \mathrm{G}(22 \mathrm{G}, 23 \mathrm{G})$ & $32(34.8 \%)$ & $22(23.9 \%)$ & $3(3.3 \%)$ & $1(1.1 \%)$ & $4(4.3 \%)$ & $2(2.2 \%)$ & \\
\hline Cell block & & & & & & & 0.483 \\
\hline Yes & $31(33.7 \%)$ & $15(16.1 \%)$ & $9(9.9 \%)$ & $1(1.1 \%)$ & $3(3.3 \%)$ & $3(3.3 \%)$ & \\
\hline No & $61(66.3 \%)$ & $47(51.1 \%)$ & $2(2.2 \%)$ & $4(4.3 \%)$ & $7(7.6 \%)$ & $1(1.1 \%)$ & \\
\hline Final diagnosis & & & & & & & 0.110 \\
\hline Malignant & $84(91.3 \%)$ & $62(67.4 \%)$ & $11(11.9 \%)$ & $5(5.4 \%)$ & $3(3.3 \%)$ & $3(3.3 \%)$ & \\
\hline benign & $8(8.7 \%)$ & $0(0.0 \%)$ & $0(0.0 \%)$ & $0(0.0 \%)$ & $7(7.6 \%)$ & $1(1.1 \%)$ & \\
\hline Experience (years) & $5.5 \pm 3.1$ & $6.2 \pm 3.0$ & $4.4 \pm 2.9$ & $2.4 \pm 2.1$ & $5.3 \pm 3.7$ & $2.8 \pm 2.2$ & 0.011 \\
\hline
\end{tabular}




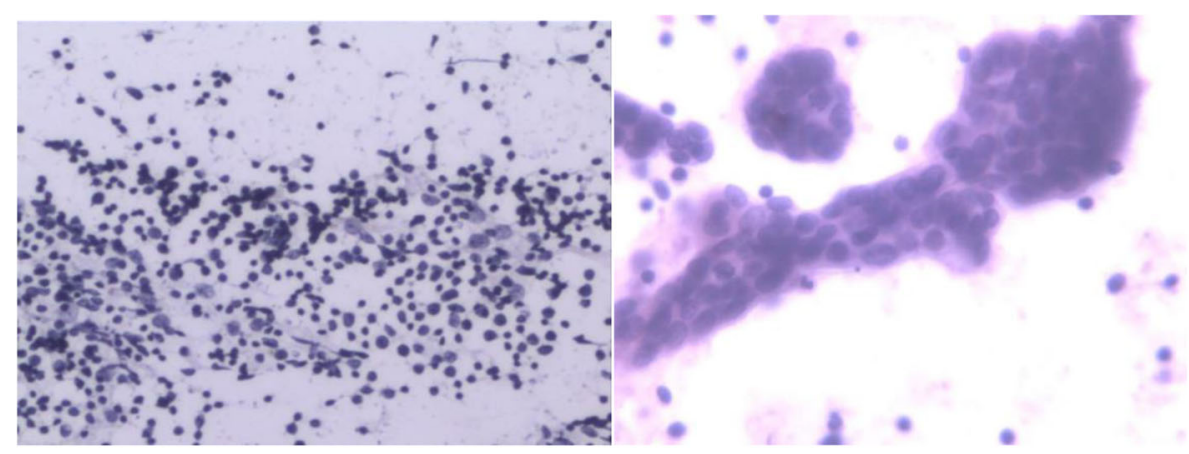

a.

b.

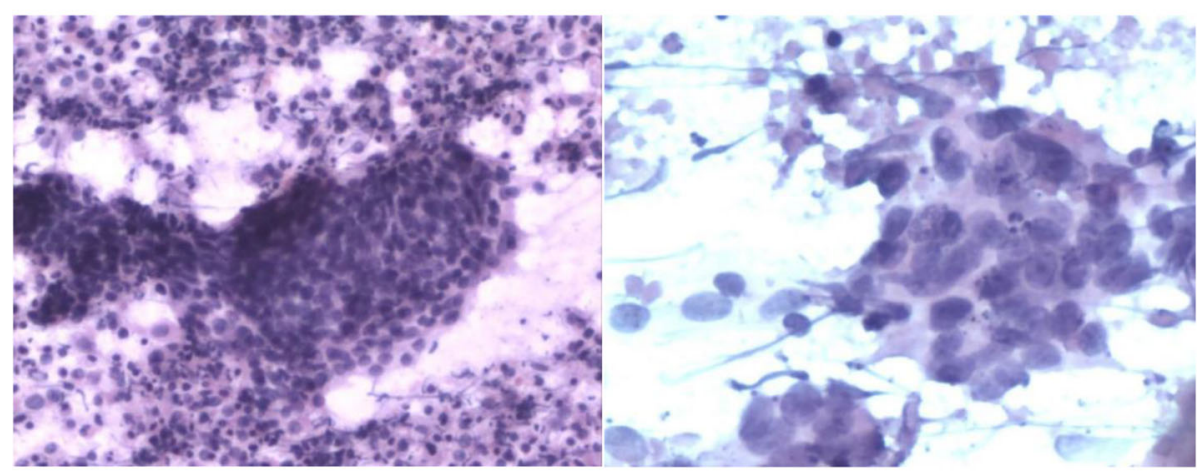

c.

d.

Fig. 4 The cytological morphology diagnosis of US-FNAC in para-aortic lymph nodes. a Cytology smear showing scattered lymphocytes and histiocytes with mixed morphology is reported as benign results (HE stain, $\times 10$ ). b Cytology smear showing glandular clusters with atypical epithelial cells scattered in the lymphocyte background is diagnosed as metastatic adenocarcinoma (HE stain, $\times 20$ ). $\mathbf{c}$ In the degenerated necrotic lymphoid tissue, there are clusters of atypical epithelial cells arranged in whirlpool, showing keratinization tendency, which is regarded as metastatic squamous cell carcinoma (HE stain, $\times 20$ ). $\mathbf{d}$ In a large necrotic background, poorly differentiated cancer cells were seen in clusters, with obvious nucleoli and unclear differentiation tendency, which is considered as metastatic undifferentiated carcinoma (HE stain, $\times 40)$

sizes were significantly reduced after treatment. Surgery was performed in five patients. Among the 10 patients with benign cytological diagnosis, three cases with features highly suggestive of malignancy based on PET/CT imaging underwent surgical biopsy and were re-diagnosed as metastatic squamous cell carcinoma. The remaining seven patients required only observation. After 12-24 months of follow-up, three patients displayed reduction in PALN size, while sizes remained stable in four patients. Among the four unsatisfactory samples and five undetermined cases, five were treated with PALN radiotherapy and systemic chemotherapy on the basis of PET/CT imaging data and three received the same therapy according to secondary US-FNAC results, which led to significant reduction in PALN size. One case with no indication of malignancy in PET/CT imaging was selected for clinical follow-up, resulting in a decrease in PALN size after 4 months. Overall, application of the US-FNAC tool affected the therapeutic methods used in 74 $(80.4 \%)$ cases.

\section{Discussion}

Results from the current study indicated that US-FNAC was useful as sonographic guidance for detection of PALNs in cervical cancer with diagnostic accuracy of $90.9 \%$, which was superior to the accuracy rate of $86.1 \%$ reported previously by Shao et al. [11] from analysis of FNAC results via CT-guided percutaneous needle biopsy of 315 patients with retroperitoneal lymphadenopathy. However, endoscopic US-guided FNAC for preoperative PALN staging in patients with pancreatobiliary cancer by Yeow et al. [17] showed that EUS-FNA had higher accuracy (98.6\%) for diagnosis of PALN metastasis, which could have clinical benefits in terms of precluding unnecessary surgery. In the present study, diagnostic sensitivity of $90.1 \%$ and accuracy of $90.9 \%$ of US-FNAC were comparable with previous findings of Stattaus et al. [18] (95.2 and 95.9\% for undetermined retroperitoneal masses) and Avritscher et al. [19] (91.4 and 92.8\% for pulmonary hilar lymph nodes).

One advantage of ultrasound guidance is that the needle tip is displayed in real time throughout the 
Table 3 The diagnostic performance of US-FNAC for PLANs in cervical cancer

\begin{tabular}{llll}
\hline Diagnostic index & Inclusion of Undetermined & Exclusion of Undetermined & $P$ value \\
\hline Sensitivity, \%(n) & $90.1 \%(73 / 81)$ & $96.1 \%(73 / 76)$ & 0.146 \\
Specificity, \%(n) & $100 \%(7 / 7)$ & $100 \%(7 / 7)$ & 1.000 \\
PPV, \%(n) & $100 \%(73 / 73)$ & $100 \%(73 / 73)$ & 1.000 \\
NPV, \%(n) & $46.7 \%(7 / 15)$ & $70.0 \%(7 / 10)$ & 0.250 \\
Accuracy, \%(n) & $90.9 \%(80 / 88)$ & $96.4 \%(80 / 83)$ & 0.145 \\
\hline
\end{tabular}

PPV Positive predictive value, NPV Negative predictive value

procedure and always remains within the lesion during sampling, thus minimizing contamination with blood and extraneous tissue (movie 1). Another advantage is that the manipulator can regulate almost any anatomical plane by angling and rotating the transducer to avoid visible blood vessels and important organs. When the needle tip is no longer visible with US during the procedure, gentle shaking of the puncture needle can facilitate tracking of the tip position (movie 2). However, USFNAC was not performed in 16 of the 24 excluded cases

Table 4 Variate analysis of the factors influencing diagnostic yield

\begin{tabular}{|c|c|c|c|c|c|c|}
\hline \multirow[t]{2}{*}{ Variables } & \multirow{2}{*}{$\begin{array}{l}\text { Correct } \\
\text { diagnosis } \\
(n=81)\end{array}$} & \multirow{2}{*}{$\begin{array}{l}\text { Wrong } \\
\text { Diagnosis } \\
(n=11)\end{array}$} & \multirow{2}{*}{$\begin{array}{l}\text { Univariate analysis } \\
P \text { value }\end{array}$} & \multicolumn{3}{|c|}{ Multivariate analysis } \\
\hline & & & & OR & $95 \% \mathrm{Cl}$ & $P$ value \\
\hline Age $[\bar{x} \pm s$ (range)](year) & $51.3 \pm 10.8$ & $53.1 \pm 11.0$ & 0.614 & 1.039 & $0.96-1.124$ & 0.344 \\
\hline Nodal size, mm & & & 0.322 & 0.333 & $0.073-1.510$ & 0.154 \\
\hline$>15 \mathrm{~mm}$ & 52 & 5 & & & & \\
\hline$\leq 15 \mathrm{~mm}$ & 29 & 6 & & & & \\
\hline Nodal number & & & 0.353 & - & - & - \\
\hline multiple & 68 & 11 & & & & \\
\hline solitary & 13 & 0 & & & & \\
\hline Nodal location & & & & 0.553 & $0.106-2.877$ & 0.481 \\
\hline Right Paraaortic & 49 & 5 & 0.352 & & & \\
\hline Left Paraaortic & 32 & 6 & & & & \\
\hline Needle gauge & & & 0.182 & 1.090 & $0.235-5.049$ & 0.913 \\
\hline$\leq 21 \mathrm{G}$ & 26 & 6 & & & & \\
\hline$\geq 22 \mathrm{G}$ & 55 & 5 & & & & \\
\hline Body mass index (BMI) & & & 0.446 & 0.187 & $0.015-2.392$ & 0.197 \\
\hline$\leq 24$ & 61 & 10 & & & & \\
\hline$>24$ & 20 & 1 & & & & \\
\hline Cell block & & & 0.498 & 1.470 & $0.212-10.20$ & 0.697 \\
\hline Yes & 26 & 5 & & & & \\
\hline No & 55 & 6 & & & & \\
\hline Nature of lymph node & & & 0.589 & - & - & - \\
\hline Malignant & 73 & 11 & & & & \\
\hline Benign & 8 & 0 & & & & \\
\hline Experience (years) & & & 0.008 & 0.077 & $0.007-0.793$ & 0.031 \\
\hline$\leq 5$ & 37 & 10 & & & & \\
\hline$>5$ & 44 & 1 & & & & \\
\hline Period & & & 0.197 & 2.501 & $0.372-16.83$ & 0.346 \\
\hline 2010-2015 & 43 & 3 & & & & \\
\hline 2016-2018 & 38 & 8 & & & & \\
\hline
\end{tabular}


in our study as the enlarged lymph nodes observed in CT imaging could not be visualized with conventional ultrasound, possibly due to small nodules, intestinal gas interference and flake growth of PALNs.

All patients underwent the US-FNAC procedure with no apparent complications. Perforation, a worrying complication often experienced during the process of abdominal FNAC, did not occur, and therefore no antibiotics were required following biopsy, consistent with earlier studies [12-14]. Owing to the considerable difficulty in distinguishing bowel from mesentery or omentum after transducer compression, we did not make an extensive effort to monitor the presence of bowels in the puncture path. Overall, the US-FNAC procedure appeared safe for clinical application.

Similar to EUS-FNA [17], percutaneous US-FNAC for PALNs is a highly challenging technique that is difficult to master for achievement of acceptable diagnostic accuracy. The success rate of US-FNAC is directly associated with the radiologist's experience in terms of years of engaging in interventional ultrasound. In the current study, among the 11 cases of incorrect diagnosis, nine of the operators had less than 3 years of experience. Practitioners must undergo a lengthy learning curve to acquire the appropriate skills to obtain good views of the target node, including selection of a suitable size needle and proper knowledge of the FNAC operating technique. Accordingly, we recommend that complex techniques should only be performed by experienced individuals with professional biopsy course training. Subsequent research [by our group] will focus on the learning curve pathway of FNAC as a reference for training.

In this study, the US-FNAC approach influenced clinical decision making for 74 patients $(80.4 \%)$. If patients exhibited PALN enlargement, para-aortic irradiation should be provided only in cases of pathological evidence of PALN metastasis to avoid spinal cord inhibition and intestinal toxicity. Encouragingly, our US-FNAC results were not false-positive, consistent with the findings of Fisher et al. [13]. If patients with cytologically benign PALN are considered for conservative observation, clinical and imaging data should be integrated [15]. Three patients with initial benign cytological diagnosis were subsequently diagnosed as metastatic squamous cell carcinoma based on surgical biopsy in our experiments. One possible interpretation for this finding is that the needle passes may not have sampled metastases owing to microscopic cancer focus. Another possibility is sampling error, whereby surgically excised metastatic PALNs were not the same aspirated lymph node. In cases where inadequate specimens were obtained, oncologists should combine clinical data and re-apply US-FNAC. Although treatment decisions are based on PET/CT imaging [15] in some patients, pathological evidence should be obtained before chemoradiotherapy to reduce unnecessary medical disputes over treatment.

The strengths of this study included the relatively large number of cervical cancer patients with PALN enlargement, concerning a high proportion with small PLANs in size. To our knowledge, this study is the first to evaluate the specific factors influencing diagnostic yield in large samples and highlight an independent predictor of diagnostic accuracy. Moreover, we have established the contributory role of US-FNAC in clinical decision making for the first time.

Our investigation also had a number of limitations that need to be considered. First, the study was retrospective in nature and had selectivity bias. Second, diagnosis and treatment of a number of patients were based on clinical follow-up and imaging data. Furthermore, this was a single-center study and the technical level was different. Ultimately, overall survival analysis was beyond the scope of this study and will be the focus of subsequent research.

In conclusion, US-FNAC was a safe and convenient technique that was widely available. The diagnostic accuracy of US-FNAC was high and the main influencing factor was the experience of the operator. Therefore, it is strongly recommended that operators undergo formal standardized training and certification of qualification. Furthermore, no false-positives and low-false negatives were obtained using this method, supporting its utility in clinical decision-making processes. The US-FNAC technique should therefore be added to standard pretherapy workup for cases of cervical cancer with enlarged paraaortic lymph nodes.

\section{Abbreviations}

US-FNAC: Ultrasound guided fine-needle aspiration cytology; PALN: Paraaortic lymph nodeDW-MRIDiffusion-weighted MR imaging; PET/CT: Positron emission tomography and computed tomography; IMA: Inferior mesenteric artery

\section{Supplementary Information}

The online version contains supplementary material available at https://doi. org/10.1186/s12885-021-08492-2.

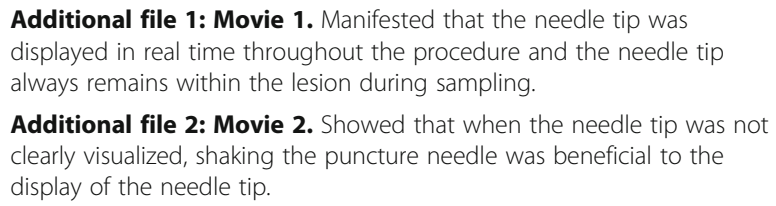

Additional file 1: Movie 1. Manifested that the needle tip was displayed in real time throughout the procedure and the needle tip always remains within the lesion during sampling.

Additional file 2: Movie 2. Showed that when the needle tip was not clearly visualized, shaking the puncture needle was beneficial to the display of the needle tip.

\section{Acknowledgements}

We thank International Science Editing (http://www.

internationalscienceediting.com) for editing this manuscript.

\section{Authors' contributions}

Study design: Liu JP, Mao WM, Wang L. Study management: Liu JP, Xu D, Wang LJ. Data collection: Liu JP, Liu X. Data analysis: Liu JP, Liu X, Guo ZY, 
Wang L. Data interpretation: Liu JP, Liu X, Guo ZY, Lv XJ. Writing: Liu JP, Liu $X$, Guo ZY, Lv XJ. Figures: Liu JP, Liu X, Lv XJ. All authors were involved in reviewing each manuscript draft and approving the final submitted version. Liu JP and Mao WM are responsible for the overall content as guarantors.

\section{Funding}

This study was supported in part by the International Cooperation Project of Zhejiang Basic Public Technology Research Program (LGJ2OH010001), Projects of Zhejiang Province Medical and Health Science and Technology Plan (2017KY256), Project of Zhejiang Basic Public Technology Research Program (LSD19H180001).

\section{Availability of data and materials}

The datasets used and/or analyzed during the current study are not publicly available due privacy rules but are available from the first author on reasonable request at the following email address liujp85@zjcc.org.cn

\section{Declarations}

\section{Ethics approval and consent to participate}

This study was approved by the Ethics Committee of Zhejiang Cancer Hospital and were in accordance with the ethical standards of the 1964 Helsinki Declaration. The need for informed consent from all patients was waived due to the study's retrospective.

\section{Consent for publication}

Not applicable.

\section{Competing interests}

No potential conflict of interest was reported by the authors.

\section{Author details}

'Department of Ultrasound, Cancer Hospital of the University of Chinese Academy of Sciences (Zhejiang Cancer Hospital), No.1 East Banshan Road, Gongshu District, Hangzhou 310022, Zhejiang Province, China. ${ }^{2}$ Department of Pathology, Cancer Hospital of the University of Chinese Academy of Sciences (Zhejiang Cancer Hospital), No.1 East Banshan Road, Gongshu District, Hangzhou 310022, Zhejiang Province, China. ${ }^{3}$ Department of Gynecologic Oncology, Cancer Hospital of the University of Chinese Academy of Sciences (Zhejiang Cancer Hospital), No.1 East Banshan Road, Gongshu District, Hangzhou 310022, Zhejiang Province, China. ${ }^{4}$ Zhejiang Key Laboratory of the Diagnosis \& Treatment Technology on Thoracic Oncology, No.1 East Banshan Road, Gongshu District, Hangzhou 310022, Zhejiang Province, China.

Received: 5 April 2021 Accepted: 14 June 2021

Published online: 27 August 2021

\section{References}

1. Shim SH, Kim DY, Lee SJ, Kim SN, Kang SB, Lee SW, et al. Prediction model for Para-aortic lymph node metastasis in patients with locally advanced cervical cancer. Gynecol Oncol. 2017;144(1):40-5. https://doi.org/10.1016/j. ygyno.2016.11.011

2. Hwang L, Bailey A, Lea J, Albuquerque K. Para-aortic nodal metastases in cervical cancer: a blind spot in the International Federation of Gynecology and Obstetrics staging system: current diagnosis and management. Future Oncol. 2015;11(2):309-22. https://doi.org/10.2217/fon.14.200.

3. Eisenhauer EA, Terasse P, Bogaerts J, et al. New response evaluation criteria in solid tumours: revised RECIST guideline (version 1.1). Eur J Cancer. 2009; 45(2):228-47. https://doi.org/10.1016/j.ejca.2008.10.026.

4. Yang WT, Lam WM, Yu MY, et al. Comparison of dynamic helical CT and dynamic MR imaging in the evaluation of pelvic lymph nodes in cervical carcinoma. AJR Am J Roentgenol. 2000;175(3):759-66. https://doi.org/1 0.2214/ajr.175.3.1750759.

5. Liu B, Gao S, Li S. A comprehensive comparison of CT, MRI, positron emission tomography or positron emission tomography/CT, and diffusion weighted imaging-MRI for detecting the lymph nodes metastases in patients with cervical Cancer: a meta-analysis based on 67 studies. Gynecol Obstet Investig. 2017;82(3):209-22. https://doi.org/10.1159/000456006.

6. Atri M, Zhang Z, Dehdashti F, Lee SI, Ali S, Marques H, et al. Utility of PET-CT to evaluate retroperitoneal lymph node metastasis in advanced cervical cancer: results of ACRIN6671/GOG0233 trial. Gynecol Oncol. 2016;142(3): 413-9. https://doi.org/10.1016/j.ygyno.2016.05.002.

7. Gee MS, Atri M, Bandos Al, Mannel RS, Gold MA, Lee SI. Identifcation of distant metastatic disease in uterine cervical and endometrial cancers with FDG PET/CT: analysis from the ACRIN 6671/GOG 0233 multicenter trial. Radiology. 2018;287(1):176-84. https://doi.org/10.1148/radiol.2017170963.

8. Brunette LL, Bonyadlou S, Ji L, Groshen S, Shuster D, Mehta A, et al. Predictive value of FDG PET/CT to detect lymph node metastases in cervical Cancer. Clin Nucl Med. 2018;43(11):793-801. https://doi.org/10.1097/RLU. 0000000000002252.

9. Achouri A, Huchon C, Bats AS, Bensaid C, Nos C, Lécuru F. Complications of lymphadenectomy for gynecologic cancer. Eur J Surg Oncol. 2013;39(1):816. https://doi.org/10.1016/j.ejso.2012.10.011.

10. De Filippo M, Saba L, Rossi E, et al. Curved needles in CT-guided fine needle biopsies of abdominal and retroperitoneal small lesions. J Vasc Interv Radiol. 2015;38(6):1611-6

11. Shao H, McCarthy C, et al. CT-guided percutaneous needle biopsy of retroperitoneal and pelvic lymphadenopathy: assessment of technique, diagnostic yield, and clinical value. J Vasc Interv Radiol. 2018;29(10):1429-36.

12. Meme OS, Dodd GD III, Esola CC. Efficacy of sonography as a guidance technique for biopsy of abdominal, pelvic and retroperitoneal lymph nodes. AJR. 1996;167(4):957-62. https://doi.org/10.2214/ajr.167.4.8819394.

13. Fisher AJ, Paulson EK, Sheafor DS, et al. Small lymph nodes of the abdomen, pelvis, and retroperitoneum: usefulness of sonographically guided biopsy. Radiology. 1997;205(1):185-90. https://doi.org/10.1148/radiology.205.1.9314 983.

14. Smith $\mathrm{EH}$. Complications of percutaneous abdominal fine-needle biopsy. Radiology. 1991;178(1):253-8. https://doi.org/10.1148/radiology.178.1.1 984314.

15. National Comprehensive Cancer Network. Cervical cancer clinical practice guidelines in oncology (2020). https://www.nccn.org/professionals/physicia n_gls/pdf/cervical.pdf.

16. Screaton NJ, Berman LH, Grant JW. Head and neck lymphadenopathy: evaluation with US-guided cutting-needle biopsy. Radiology. 2002;224(1): 75-81. https://doi.org/10.1148/radiol.2241010602.

17. Kurita A, Kodama Y, Nakamoto Y, Isoda H, Minamiguchi S, Yoshimura K, et al. Impact of EUS-FNA for preoperative Para-aortic lymph node staging in patients with pancreatobiliary cancer. Gastrointest Endosc. 2016;84(3):46775. https://doi.org/10.1016/j.gie.2016.02.045.

18. Stattaus J, Kalkmann J, Kuehl H, Metz KA, Nowrousian MR, Forsting M, et al. Diagnostic yield of computed tomography-guided coaxial core biopsy of undetermined masses in the free retroperitoneal space: single-center experience. Cardiovasc Intervent Radiol. 2008;31(5):919-25. https://doi.org/1 0.1007/s00270-008-9317-5.

19. Avritscher R, Krishnamurthy S, Ensor J, Gupta S, Tam A, Madoff DC, et al. Accuracy and sensitivity of computed tomography-guided percutaneous needle biopsy of pulmonary hilar lymph nodes. Cancer. 2010;116(8):197480. https://doi.org/10.1002/cncr.24968.

\section{Publisher's Note}

Springer Nature remains neutral with regard to jurisdictional claims in published maps and institutional affiliations.

\section{Ready to submit your research? Choose BMC and benefit from:}

- fast, convenient online submission

- thorough peer review by experienced researchers in your field

- rapid publication on acceptance

- support for research data, including large and complex data types

- gold Open Access which fosters wider collaboration and increased citations

- maximum visibility for your research: over $100 \mathrm{M}$ website views per year

At BMC, research is always in progress.

Learn more biomedcentral.com/submissions 